\title{
AR SECO E AQUECIDO NO PROCESSO DE DORMÊNCIA E GERMINAÇÃO DE SEMENTES DE Urochloa humidicola
}

\author{
Antonio Marcelo Pereira ${ }^{1}$, Fabiane Lima Abrantes ${ }^{2}$, Nelson Barbosa Machado-Neto ${ }^{2}$, Ceci Castilho \\ Custódio $^{2}$ \\ ${ }^{1}$ Itesp. ${ }^{2}$ Universidade do Oeste Paulista - UNOESTE, Faculdade de Agronomia, Presidente Prudente-SP. E-mail: \\ ceci@unoeste.br
}

\section{RESUMO}

$\mathrm{O}$ ácido sulfúrico $\left(\mathrm{H}_{2} \mathrm{SO}_{4}\right)$ mostra-se eficaz na superação da dormência em sementes, porém trazendo riscos efetivos aos trabalhadores e ambiente. O objetivo do trabalho foi estudar a efetividade do tratamento com ácido sulfúrico, preconizado pelas RAS, e o emprego de ventilação com ar seco e aquecido na superação da dormência e desempenho germinativo de sementes de seis lotes de Urochloa humidicola cv. Tully. Os efeitos fisiológicos entre tratamentos térmicos (45, 55,65 e $75 \stackrel{\circ}{\circ}$ ), por 24 ou $48 \mathrm{~h}$, a escarificação com $\mathrm{H}_{2} \mathrm{SO}_{4}$ concentrado por 10 min e um controle, foram comparados pela germinação, o índice de velocidade de germinação, o teste de tetrazólio e a massa seca das plântulas. $\mathrm{O}$ uso de temperaturas variadas e controladas e de $\mathrm{H}_{2} \mathrm{SO}_{4}$ são mecanismos de superação de dormência, porém em lotes com maior vitalidade os resultados foram similares ao $\mathrm{H}_{2} \mathrm{SO}_{4}$, podendo ser considerado uma alternativa. De maneira geral, o trabalho não indicou o melhor período ( 24 ou $48 \mathrm{~h}$ ), para emprego da ventilação com ar seco, entretanto a temperatura de $60{ }^{\circ} \mathrm{C}$, para os lotes de maior vitalidade (L1, L3 e L5), pode ser recomendada. $\mathrm{O}$ $\mathrm{H}_{2} \mathrm{SO}_{4}$ nos lotes com maior vitalidade não mostrou significância estatística em relação à testemunha, porém para os lotes com menor vitalidade ocorreu deterioração fisiológica das sementes.

Palavras-chave: ácido sulfúrico; ar aquecido; Quícuio da Amazônia; secagem; vigor de sementes.

\section{DRY AND HEATED AIR IN THE PROCESS OF DORMANCY OVERCOMING AND GERMINATION OF Urochloa humidicola}

\begin{abstract}
Sulfuric acid $\left(\mathrm{H}_{2} \mathrm{SO}_{4}\right)$ has shown effectiveness in overcoming dormancy, but its use carries effective workers and environmental risks. The objective of this work was to study the sulfuric acid treatment effectiveness, recommended by the RAS, and the use of ventilation with dry, heated air to overcome the dormancy and germination performance of six seed lots Urochloa humidicola cv. Tully. Comparison between the physiological effects of heat treatments at $45,55,65$ and 75 o $\mathrm{C}$, with periods 24 and $48 \mathrm{~h}$ and chemical scarification (immersion in concentrated $\mathrm{H}_{2} \mathrm{SO}_{4}$ ) for 10 min, constituting eight treatments and two controls was performed. The seed germination, the germination velocity index, the tetrazolium test and seedling dry weight was evaluated. The use of controlled temperatures and of $\mathrm{H}_{2} \mathrm{SO}_{4}$ are mechanisms to overcome dormancy, but in lots with greater vitality were equal to conventional treatment with sulfuric acid results and can be considered as an alternative. In general, the work did not show the best indicated time (24 or 48 h) for use with dry air ventilation, however a temperature of $60{ }^{\circ} \mathrm{C}$ for lots of high vitality (L1, L3 and L5) might be recommended. The $\mathrm{H}_{2} \mathrm{SO}_{4}$ in plots with high vitality was not statistically significant compared to control, but for lots with less vitality occurred physiological deterioration of seeds.
\end{abstract}

Key words: sulfuric acid; heated air; drying; Quícuio da Amazônia; seed vigor. 


\section{INTRODUÇÃO}

A produção de carne e leite no Brasil é feita em grandes áreas de pastagens, ocupando 172 milhões de hectares (IBGE, 2006) e aproximadamente 55\% (94 milhões de hectares) destas áreas são cultivada (FERRAZ, 2003). As áreas dedicadas à pecuária ocupam $20 \%$ do território nacional contra apenas $10 \%$ das áreas agrícolas (IBGE, 2006).

A Urochloa humidicola (syn. Brachiaria humidicola) também conhecida como "Quícuio da Amazônia" é nativa do leste e sudeste da África tropical, especialmente de zonas com altas precipitações, perene, estolonífera, de hábito de crescimento semiereto a prostrado, com grande número de gemas rente ao solo, o que explica sua tolerância a manejo baixo e intenso, suportando altas cargas animais e elevada adaptabilidade a solos com problemas de encharcamento e/ou de baixa qualidade química como os do cerrado, pantanal e algumas partes da região norte do Brasil. Tem uma velocidade de cobertura de solo bastante lenta, por apresentar sementes com dormência que corrobora para a desuniformidade na germinação (PIRES, 2006).

O mecanismo de dormência apresenta peculiaridades para diferentes espécies, e até problemas de conceituação (THOMPSON; OOI, 2010), tornando-se difícil qualquer generalização sobre suas causas, as quais podem ocorrer independentemente, ou combinadas, como acontece para a maioria das sementes de gramíneas forrageiras (MESCHEDE et al., 2004), e nas tropicais, a dormência esta associada a causas fisiológicas ou físicas, nas sementes recémcolhidas, as quais são progressivamente suprimidas durante $\mathrm{o}$ armazenamento (ALMEIDA; SILVA, 2004; USBERTI, 2007).

Trabalhos experimentais têm sido elaborados com o intuito de promover a germinação em sementes de gramíneas forrageiras, por meio do método de escarificação química com ácido sulfúrico concentrado $\left(\mathrm{H}_{2} \mathrm{SO}_{4}\right)$ (MARTINS; SILVA, 2006; USBERTI; MARTINS, 2007). Este método é usualmente empregado para sementes duras, impermeáveis à água (BRASIL, 2009) que, apesar de eficiente, pode gerar prejuízos aos trabalhadores operacionalmente envolvidos, à qualidade das sementes e ao meio ambiente. Sallum et al. (2010) verificaram que essa prática reduziu a dormência, sem prejuízos à qualidade em sementes de $U$. brizantha armazenadas por 6 meses. A adequada eficiência do método, apesar de verificada em $U$. brizantha (SALLUM et al., 2010), foi menos evidente em U. decumbens (GONZÁLEZ et al., 1994) e nula ou negativa em $U$. humidicola (MACEDO et al., 1994). 
Prejuízos fisiológicos latentes após o armazenamento, relacionados com a mortalidade das sementes escarificadas com ácido sulfúrico, foram observados por Macedo et al. (1994) em sementes de $U$. humidicola, González et al. (1994) em U. decumbens e por Sallum et al. (2010) em U. brizantha após 9 meses de armazenamento. Dessa forma, foi possível verificar que alguns procedimentos capazes de favorecer a redução da dormência e a elevação imediata do desempenho agronômico podem, com o passar do tempo, contribuir para a deterioração das sementes. Segundo Foloni et al. (2009) sementes escarificadas com ácido sulfúrico foram menos tolerantes ao contato com adubação, na semeadura objetivando integração lavoura pecuária (ILP).

Pesquisas sobre a remoção da dormência em sementes de gramíneas forrageiras têm considerado a ação de temperaturas elevadas e observado resultados semelhantes aos obtidos no tratamento com ácido sulfúrico para a superação da dormência (MARTINS; SILVA, 2006; MARTINS; SILVA, 2003; ALMEIDA; SILVA, 2004).

Estudando os efeitos da exposição de sementes de Urochloa dictyoneura cv. Llanero a $85{ }^{\circ} \mathrm{C}$ por 10 e $15 \mathrm{~h}$ Almeida e Silva (2004) concluíram que o uso do calor constitui-se em alternativa para a redução da dormência, Martins et al. (1997) com exposição das sementes à $80{ }^{\circ} \mathrm{C}$ por $10 \mathrm{~h}$ e Martins e Silva (2001) com 70 e $85{ }^{\circ} \mathrm{C}$ por 5 , 10 e 15 h em sementes de Urochloa brizantha cv. Marandu também observaram que os tratamentos proporcionaram à diminuição da taxa de dormência.

Embora tenham verificado resultados satisfatórios nos estudos sobre a remoção da dormência com o emprego de altas temperaturas em sementes de Urochloa permanecem dúvidas com relação à quantidade do calor e do período de exposição das sementes à temperatura elevada, nas diferentes espécies de Urochloa para que seus efeitos se aproximem dos obtidos com a utilização do ácido sulfúrico.

As informações sobre sementes de Urochloa humidicola ainda são escassas e considerando os resultados positivos obtidos no tratamento térmico e os inconvenientes relacionados à utilização do ácido sulfúrico na superação da dormência das sementes, o objetivo deste trabalho foi estudar a efetividade do tratamento com ácido sulfúrico, preconizado pelas RAS, e o emprego de ventilação com ar seco e aquecido na superação da dormência e desempenho germinativo de sementes de seis lotes desta espécie. 


\section{MATERIAL E MÉTODOS}

A pesquisa foi realizada utilizando seis lotes de sementes de $U$. humidicola (Rendle) Schw. cv. Tully, sendo três lotes recémcolhidos com maior vitalidade e dormência (2010/2011) e três lotes com menor vitalidade e dormência (2009/2010), as quais foram limpas eliminando as impurezas, sementes chochas e de plantas invasoras, restando somente sementes fisicamente puras (BRASIL, 2009), as quais foram armazenadas em ambiente de laboratório, a $25 \pm 3{ }^{\circ} \mathrm{C}$ e $60 \%$ de UR, durante a fase de aplicação e avaliação dos tratamentos. Avaliações preliminares, conduzidas pelo teste de tetrazólio e fornecidas pelas empresas indicaram resultados de 71, 69 e $60 \%$ para os lotes L1, L3 e L5 e 47, 30 e $31 \%$ para os lotes $L 2$, $L 4$ e $L 6$, respectivamente.

O experimento constou do uso de ventilação com ar seco e aquecido à 45,55 , 65 e $75 \stackrel{\circ}{ } \mathrm{C}$, por 24 e 48 h, em estufa com circulação de ar. Após, os tratamentos as sementes foram avaliadas por análises fisiológicas. Duas testemunhas, uma sem tratamento e outra imersa em ácido sulfúrico concentrado $98 \%$ por 10 min seguidos de neutralização em água corrente por igual período (BRASIL, 2009) foram considerados controles dos tratamentos térmicos. Neste experimento foram realizadas as seguintes avaliações:
Teste de germinação conduzido com quatro subamostras de 100 sementes por tratamento, em caixas de plástico transparente $(11 \times 11 \times 3,5 \mathrm{~cm}$ - tipo germibox) com duas folhas de papel mataborrão umedecidas com água, na proporção de duas vezes a massa do papel seco e colocado para germinar de acordo com as Regras para Análise de Sementes - RAS, e as leituras foram realizadas aos 7, 14 e 21 dias considerando-se a obtenção de plântulas normais e anormais como descrito em Brasil (2009). Obteve-se a porcentagem de germinação $(\% \mathrm{G})$ e o índice de velocidade de germinação (IVG). Ao final do teste de germinação as sementes remanescentes não germinadas foram submetidas ao teste de tetrazólio para avaliação e caracterização em sementes dormentes e mortas (BRASIL, 2009). A porcentagem de sementes remanescentes dormentes foi considerada aquelas com as partes vitais do embrião coloridas pelo tetrazólio.

O teste de tetratozólio foi conduzido conforme descrito por Custódio et al. (2012) com as sementes remanescentes não germinadas aos 21 dias de condução do teste de germinação, em duas repetições por tratamento. As sementes foram avaliadas considerando-se a localização e a intensidade da coloração de suas partes, permitindo identificar as sementes com as partes vitais do embrião coloridas, que foram 
consideradas vivas (BRASIL, 2009) e denominadas sementes remanescentes dormentes.

O índice de velocidade de germinação IVG foi calculado pela fórmula IVG $=\mathrm{G} 1 / \mathrm{N} 1+\mathrm{G} 2 / \mathrm{N} 2+\mathrm{G} 3 / \mathrm{N} 3$; onde, G1, G2 e G3, são os números de plântulas computadas na primeira, na segunda e na última contagem; e N1, N2 e N3, são os números de dias após a semeadura, na primeira, segunda e na última contagem (NAKAGAWA, 1999).

A massa seca de plântula foi obtida em cada avaliação do teste de germinação e em cada repetição pela secagem em estufa a 65 ${ }^{\circ} \mathrm{C}$ por $48 \mathrm{~h}$, das plantas normais retiradas do substrato e destacadas das partes remanescentes da cariopse.

O experimento foi conduzido com delineamento casualizado com quatro repetições. $\mathrm{Na}$ primeira análise consideraram-se apenas os tratamentos térmicos arranjados em esquema fatorial ( $4 \mathrm{x}$ 2), sendo quatro temperaturas e dois períodos de exposição ao calor para a análise de variância (teste F) e aplicação de regressão polinomial para cada lote. $\mathrm{Na}$ segunda análise, considerou-se todas as combinações dos tratamentos térmicos (8 tratamentos) e os dois tratamentos controle (testemunha e sementes tratadas com ácido sulfúrico) para a análise de variância (teste F) e comparação de médias pelo teste de Tukey a 5\% de significância. A avaliação de sementes remanescentes dormentes foi realizada por estatística descritiva com cálculo da média e desvio padrão. Os dados porcentuais de germinação foram transformados em arco seno $(x / 100)^{1 / 2}$, pois originalmente não seguiram distribuição normal. Utilizou-se o programa estatístico SISVAR $^{\circledR}$ (FERREIRA, 2011) para realização das análises.

\section{RESULTADOS E DISCUSSÃO}

A quantidade total de sementes vivas em um lote é fundamental para sua caracterização e discussão dos demais resultados obtidos em função da aplicação dos tratamentos. A instrução normativa № 30, de 21 de maio de 2008, que estabelece padrões para produção e comercialização de sementes de gramíneas (Poaceae/Gramineae), determina, como germinação mínima $40 \%$ para $U$. humidicola (BRASIL, 2008).

$\mathrm{Na}$ análise da germinação, considerando apenas os tratamentos térmicos (Figura 1) foi possível notar que a germinação do lote 1 não foi responsiva aos períodos e temperaturas empregadas. No lote 3 , os períodos não diferiram, porém ocorreu um ajuste quadrático significativo com ponto de máximo aos $59,6{ }^{\circ} \mathrm{C}$. E para o lote 5 , também não ocorreu diferença entre os períodos de 24 e 48 h, porém o ajuste foi linear crescente indicando acréscimo na 
germinação com o emprego de tratamentos com temperaturas maiores.

Em relação aos lotes considerados de baixa vitalidade, verificou-se que no lote 2 , não houve resposta em função das temperaturas, mas o período de $24 \mathrm{~h}$ foi superior ao de 48 h. No entanto para o lote 4 , não ocorreu diferenças entre os períodos de 24 e 48 h, mas o uso de temperaturas crescentes reduziram a germinação como expresso pelo ajuste linear decrescente. E no lote 6 , o período de $48 \mathrm{~h}$ foi superior ao de $24 \mathrm{~h}$, enquanto o aumento da temperatura de tratamento não foi significativo (Figura 1). Como os lotes apresentavam menor vitalidade, a resposta de germinação sempre foi inferior ao necessário para comercialização de sementes (BRASIL, 2008).

O calor aplicado às sementes induz primeiramente a dessecação, ou seja, perda de água pelos tecidos da semente como aconteceu em experimentos anteriores que também empregaram calor seco em sementes de $U$. brizantha cv. Marandu (MARTINS; SILVA, 2003). Concomitantemente a perda de água, outras alterações podem ocorrer nas sementes durante a dessecação, síntese de proteínas lea (late embryogenesis accumulated) (VERDOY et al., 2004) e a habilidade para prevenir, tolerar ou reparar ataque de espécies reativas de oxigênio - ROS (GREGGAINS et al., 2001). 

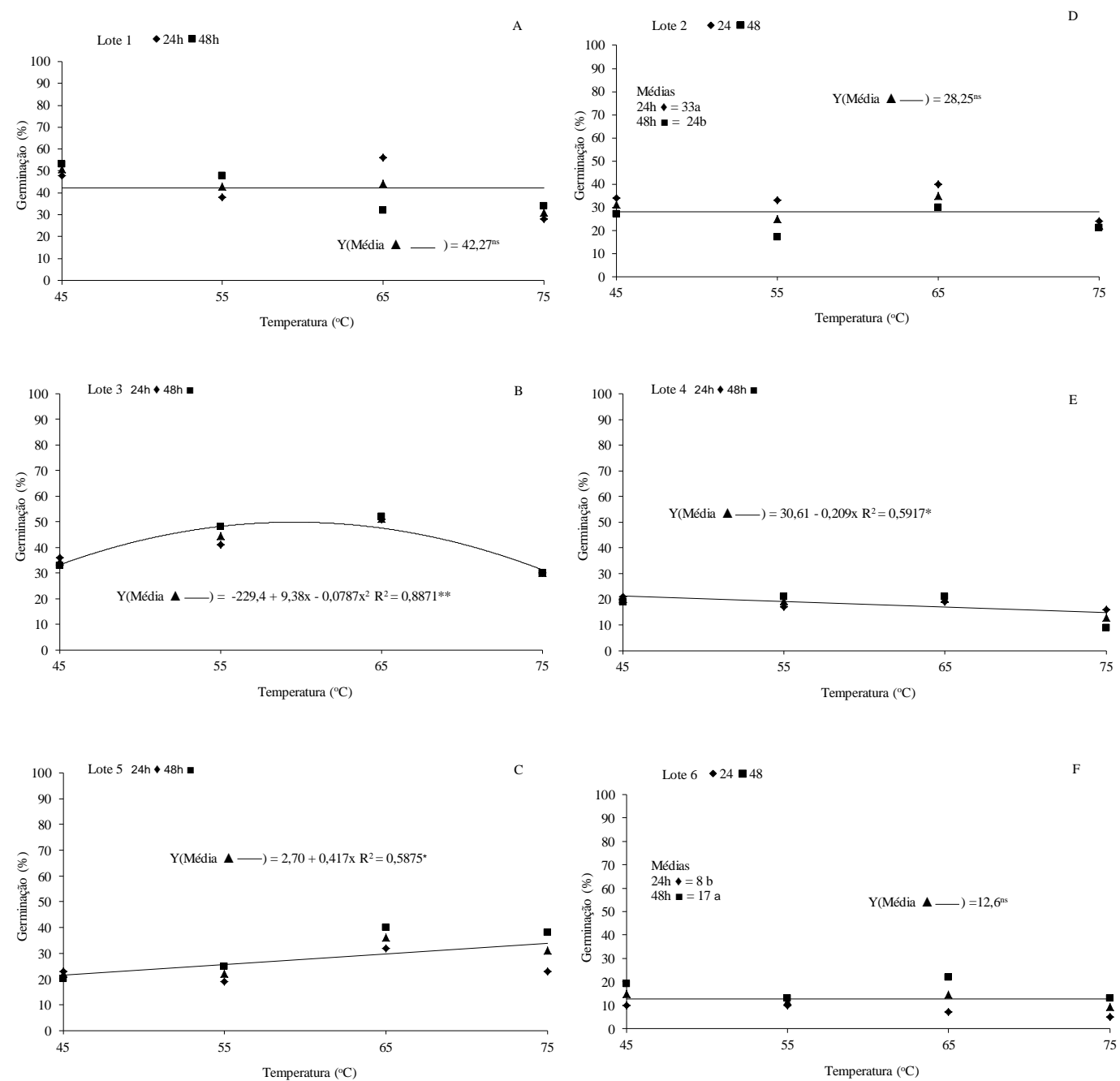

Figura 1. Germinação $(G)$ de sementes de três lotes (L1, $L 3$ e $L 5)$ de alta vitalidade e de três lotes (L2, L4 e L6) de baixa vitalidade de U. humidicola cv. Tully em função de períodos de permanência sob ventilação com ar seco aquecido.

Por outro lado, pesquisas têm revelado um papel regulatório dos ROS na germinação, bloqueando-a ou promovendo a superação da dormência (ORACZ et al., 2007). Resultados obtidos com girassol permitiram a proposição de um mecanismo de superação de dormência o qual envolve mudança na oxidação de proteínas, em consequência no acúmulo de ROS. Assim, este acúmulo parece ser o sinal chave governando a atividade celular e pode ser um modelo geral, em vista de resultados similares obtidos durante a superação de dormência em sementes, no estado seco e embebidas (ORACZ et al., 2007).

ROS são continuamente produzidas durante a formação da semente, da embriogênese a germinação, e também durante o armazenamento, desempenhando um duplo papel na fisiologia das sementes, como ator em rotas de sinalização, ou como produto tóxico acumulado sob condição de 
estresse, como ocorre em condições de temperatura elevada. A quantidade de ROS é estreitamente regulada pelo balanço entre produção e remoção, parecendo agir como um sinal positivo para superação da dormência de sementes. Assim, é apresentado o conceito de "janela oxidativa para germinação" (JOG) restringindo a ocorrência de eventos celulares associados à germinação a uma faixa crítica de nível de ROS. Acima ou abaixo da JOG, baixos ou altos conteúdos de ROS, respectivamente, não permitem o progresso da germinação e o incontrolado acúmulo de ROS acarreta dano oxidativo afetando muitas macromoléculas e culminando com morte celular (BAILLY et al., 2008).

Face aos resultados obtidos com tratamentos térmicos, pode-se inferir que lotes com menor quantidade de sementes vivas (L2, L4 e L6) pouco responderam, pois estavam em elevado grau de deterioração e o calor seco contribuiu para o acúmulo de danos. No entanto, lotes com mais sementes viáveis (L1, L3 e L5) apresentaram alguns resultados promissores como os pontos de máximo obtidos para o lote 3 e as respostas lineares crescentes obtidas para o lote 5 . Estes resultados seriam explicados por meio da JOG (Figura 1, BAILLY et al., 2008).

$\mathrm{Na}$ análise considerando todos os tratamentos térmicos e os dois tratamentos controle, observou-se que, na germinação do lote 1 , os tratamentos com período de $24 \mathrm{~h}$ e temperaturas de 45 e $65^{\circ} \mathrm{C}$ e período de $48 \mathrm{~h}$ com temperatura de 45 e $55{ }^{\circ} \mathrm{C}$ não diferiram estatisticamente do tratamento com $\mathrm{H}_{2} \mathrm{SO}_{4}$ e da testemunha. Sendo que o tratamento de período de $24 \mathrm{~h}$ com temperaturas de 55 e $75{ }^{\circ} \mathrm{C}$ e o tratamento de $48 \mathrm{~h}$ com temperaturas de 65 e $75{ }^{\circ} \mathrm{C}$ foram inferiores à testemunha e ao tratamento convencional (Tabela 1).

Para o lote 3 (Tabela 1), no período de $24 \mathrm{~h}$ apenas o tratamento com temperatura de $65{ }^{\circ} \mathrm{C}$ e no período de $48 \mathrm{~h}$ com temperaturas de 55 e $65{ }^{\circ} \mathrm{C}$ não diferiram estatisticamente do tratamento com $\mathrm{H}_{2} \mathrm{SO}_{4} \mathrm{e}$ da testemunha, os demais tratamentos foram inferiores à testemunha e ao $\mathrm{H}_{2} \mathrm{SO}_{4}$.

No lote 5 nenhum tratamento realizado foi melhor que a testemunha, e em comparação com $\mathrm{O} \quad \mathrm{H}_{2} \mathrm{SO}_{4}$, apenas $\mathrm{O}$ tratamento de período de $48 \mathrm{~h}$ com as temperaturas de 65 e $75{ }^{\circ} \mathrm{C}$ não diferiram do tratamento convencional (Tabela 1).

Para o lote 2, no tratamento com período de $24 \mathrm{~h}$, apenas a temperatura de 75 ${ }^{\circ} \mathrm{C}$ foi inferior a testemunha, porem não diferiu estatisticamente do tratamento com $\mathrm{H}_{2} \mathrm{SO}_{4}$. No período de $48 \mathrm{~h}$ com temperaturas de 45 e $65{ }^{\circ} \mathrm{C}$ não diferiram estatisticamente da testemunha, porém tiveram resultados superiores ao tratamento convencional (Tabela 1).

Para o lote 4, o tratamento com período de $24 \mathrm{~h}$ todas as temperaturas foram superiores ao tratamento com $\mathrm{H}_{2} \mathrm{SO}_{4}$ e a 
testemunha. No período de $48 \mathrm{~h}$ às temperaturas de 45,55 e $65{ }^{\circ} \mathrm{C}$ foram superiores aos controles. Na temperatura de $75{ }^{\circ} \mathrm{C}$ por $48 \mathrm{~h}$, a testemunha e o tratamento convencional, foram inferiores aos demais tratamentos térmicos. Para o lote 6, não houve significância estatística dos tratamentos utilizados em relação aos controles (Tabela 1).

Tabela 1. Resultados de germinação (\%) de sementes de seis lotes de U. humidicola cv. Tully.

\begin{tabular}{|c|c|c|c|c|c|c|c|c|}
\hline \multicolumn{2}{|c|}{ Tratamentos } & $\mathbf{L 1}$ & L3 & L5 & L2 & L4 & L6 & Médias \\
\hline $\mathbf{P}$ & $\mathbf{T}$ & \multicolumn{7}{|c|}{ (\%) } \\
\hline \multirow[t]{4}{*}{24} & 45 & $48 a^{1}$ & $36 \mathrm{~b}$ & $23 c$ & $34 a$ & $21 \mathrm{a}$ & $10 \mathrm{a}$ & 29 \\
\hline & 55 & $38 \mathrm{~b}$ & $41 \mathrm{~b}$ & $19 c$ & $33 a$ & $17 a$ & $10 \mathrm{a}$ & 26 \\
\hline & 65 & $56 a$ & $51 \mathrm{a}$ & $32 \mathrm{c}$ & $40 \mathrm{a}$ & $19 a$ & $7 a$ & 34 \\
\hline & 75 & $28 \mathrm{~b}$ & $30 \mathrm{~b}$ & $23 c$ & $24 \mathrm{~b}$ & $16 a$ & $5 a$ & 21 \\
\hline \multirow[t]{4}{*}{48} & 45 & $53 a$ & $33 \mathrm{~b}$ & $20 \mathrm{c}$ & $27 a$ & $19 \mathrm{a}$ & $19 \mathrm{a}$ & 29 \\
\hline & 55 & $48 \mathrm{a}$ & $48 \mathrm{a}$ & $25 \mathrm{c}$ & $17 \mathrm{~b}$ & $21 \mathrm{a}$ & $13 \mathrm{a}$ & 29 \\
\hline & 65 & $32 b$ & $52 \mathrm{a}$ & $40 \mathrm{~b}$ & $30 \mathrm{a}$ & $21 \mathrm{a}$ & $22 \mathrm{a}$ & 33 \\
\hline & 75 & $34 \mathrm{~b}$ & $30 \mathrm{~b}$ & $38 \mathrm{~b}$ & $21 b$ & $9 \mathrm{~b}$ & $13 \mathrm{a}$ & 24 \\
\hline \multicolumn{2}{|c|}{ Testemunha } & $51 \mathrm{a}$ & $52 a$ & $55 a$ & $31 \mathrm{a}$ & $11 \mathrm{~b}$ & $13 \mathrm{a}$ & 36 \\
\hline \multicolumn{2}{|c|}{$\mathrm{H}_{2} \mathrm{SO}_{4}$} & $51 \mathrm{a}$ & $54 \mathrm{a}$ & $45 \mathrm{~b}$ & $17 \mathrm{~b}$ & $\mathrm{Ob}$ & $5 a$ & 29 \\
\hline
\end{tabular}

\begin{tabular}{lllllll}
\hline Médias & 44 & 43 & 32 & 27 & 15 & 12
\end{tabular}

$\mathrm{P}=$ período $(\mathrm{h}) ; \mathrm{T}=$ temperatura $\left({ }^{\circ} \mathrm{C}\right) ; \mathrm{L}=$ lotes. ${ }^{1}$ Médias seguidas por mesma letra minúscula, na coluna, não diferem pelo teste Scott-Knott, com $5 \%$ de significância.

Embora as Regras para Análise de Sementes (BRASIL, 2009) recomendem a utilização de ácido sulfúrico concentrado por 10 min para escarificação de sementes de $U$. humidicola, Macedo et al. (1994) concluíram que este tratamento, nessa espécie, é prejudicial à germinação. Todavia, Sallum et al. (2010) constataram que o mesmo foi efetivo para superar a dormência em sementes de $U$. brizantha cv. Marandu. Contudo, devem ser consideradas as inconveniências relacionadas à segurança do trabalhador, e ainda, à preservação do ambiente com o descarte dos resíduos ou mesmos os gastos com a correta disposição.
Almeida e Silva (2004), estudando os efeitos da exposição de sementes de Urochloa dictyoneura cv. Llanero a $85{ }^{\circ} \mathrm{C}$ por 10 e 15 h, concluíram que o uso do calor constitui-se em alternativa para a redução da dormência. Da mesma forma, aplicações de 70 e $85{ }^{\circ} \mathrm{C}$ por 5,10 e $15 \mathrm{~h}$ em sementes de Urochloa brizantha cv. Marandu reduziram a taxa de dormência (MARTINS; SILVA, 2006).

Por outro lado, estudando diferentes métodos para superação da dormência do cultivar Marandu, Montório et al. (1997) afirmaram que a escarificação com ácido sulfúrico concentrado promoveu os melhores resultados quanto ao vigor das sementes. No 
entanto, a imersão em água destilada, à temperatura ambiente e retirada das glumas, pode substituir a escarificação ácida das sementes dessa espécie. A remoção das glumas das sementes quer seja química, via escarificação ácida como em $U$. brizantha e U. decumbens (FOLONI et al., 2009; SALLUM et al., 2010; CUSTÓDIO et al., 2011) ou mecânica como em $U$. brizantha, $U$. decumbens e U. humidicola (HOPKINSON; ENGLISH, 2005) é tratamento eficiente na superação de dormência destas espécies.

A explicação para o sucesso da escarificação, tanto ácida quanto mecânica, está relacionada à dormência que, no caso do gênero Urochloa, ocorre geralmente sob duas formas: de caráter fisiológicobioquímico, de curta duração, observada quase sempre em sementes recém-colhidas; e a chamada dormência relacionada à presença de envoltórios que dificultam a difusão de oxigênio no processo de germinação, geralmente de longa duração (LIMA; CARDOSO, 1996).

Embora tenham sido aplicados tratamentos para superação da dormência, os resultados de sementes remanescentes dormentes permitiram indicar que restaram sementes dormentes em todos os tratamentos e, em alguns casos, ocorreu aumento de sementes dormentes em comparação à testemunha. Os maiores valores foram observados no tratamento por $24 \mathrm{~h}$ na temperatura de $75^{\circ} \mathrm{C}$ para os lotes 1 , 3 e 5 . Em geral os tratamentos térmicos apresentaram maior dormência que o tratamento testemunha, enquanto os menores valores de sementes remanescentes dormentes foram observados no tratamento com $\mathrm{H}_{2} \mathrm{SO}_{4}$ (Tabela 2).

Em sorgo, altas temperaturas podem estar associadas com a indução de dormência secundária, a secagem a $45^{\circ} \mathrm{C}$ e posterior armazenamento em condições convencionais induziu este fenômeno (SILVA et al., 2011). A termoinibição de sementes embebidas que são expostas a temperaturas supra-ótimas é fenômeno observado em um grande número de táxons (WATT; BLOOMBERG, 2012) e é atribuída a restrição física (FINCH-SAVAGE; LEUBNER-METZGER, 2006) ou a maior exigência de potencial hídrico para a germinação (ALVARADO; BRADFORD, 2002) que impedem o crescimento do embrião dentro da semente, e não a explicação mais comum que é a desnaturação de enzimas devido à temperatura excessiva (WATT; BLOOMBERG, 2012). 
Tabela 2. Número de sementes remanescentes dormentes ${ }^{1}(\%)$ de três lotes de U. humidicola cv. Tully.

\begin{tabular}{lcccc}
\hline $\begin{array}{l}\text { Tratamentos } \\
\mathbf{P}\end{array}$ & $\mathbf{T}$ & $\mathbf{L 1}$ & $\mathbf{L 3}$ & $\mathbf{L 5}$ \\
\cline { 2 - 5 } 24 & 45 & $8 \pm 4,24^{2}$ & $18 \pm 7,07$ & $5 \pm 0,71$ \\
& 55 & $20 \pm 17,68$ & $14 \pm 3,53$ & $14 \pm 4,95$ \\
& 65 & $9 \pm 12,73$ & $6 \pm 2,83$ & $10 \pm 0,01$ \\
48 & 75 & $44 \pm 4,95$ & $32 \pm 14,85$ & $19 \pm 0,71$ \\
& 45 & $13 \pm 7,78$ & $16 \pm 10,60$ & $10 \pm 6,37$ \\
& 55 & $9 \pm 4,95$ & $18 \pm 4,24$ & $9 \pm 7,78$ \\
& 65 & $9 \pm 12,73$ & $8 \pm 5,66$ & $13 \pm 7,07$ \\
Testemunha & 75 & $16 \pm 4,24$ & $8 \pm 2,12$ & $7 \pm 1,41$ \\
$\mathrm{H}_{2} \mathrm{SO}_{4}$ & & $5 \pm 2,83$ & $15 \pm 12,73$ & $9 \pm 2,12$ \\
$\mathrm{P}_{4}$ & & $5 \pm 3,53$ & $1 \pm 1,41$ & $2 \pm 2,83$ \\
\hline
\end{tabular}

$\mathrm{P}=$ período $(\mathrm{h}) ; \mathrm{T}=$ temperatura $\left({ }^{\circ} \mathrm{C}\right) ; \mathrm{L}=$ lotes. ${ }^{1}$ Sementes remanescentes, com as partes vitais do embrião coloridas pelo teste de tetrazólio, no teste de germinação (\%). ${ }^{2}$ Médias seguidas por desvio padrão (2 repetições).

Nos lotes com menor vitalidade também restaram sementes dormentes após o término do teste de germinação. As sementes sem tratamento (testemunha) apresentaram 11, 10 e $9 \%$ de sementes dormentes nos lotes 2, 4 e 6, respectivamente. Os tratamentos térmicos, em geral, apresentaram valores próximos ao da testemunha enquanto o tratamento com ácido sulfúrico foi o que deixou menos sementes dormentes para os lotes 2,4 e 6 (Tabela 3).

Em sementes ortodoxas, como é o caso das sementes de $U$. humidicola, a aplicação de temperaturas acima de $42{ }^{\circ} \mathrm{C}$ é rotineiramente associada com deterioração, no entanto os resultados obtidos por Almeida e Silva (2004) e Martins e Silva (2006) aplicaram o calor seco para redução da dormência em forrageiras tropicais com sucesso. Usberti (2007) utilizou alta temperatura de armazenamento em sementes intactas e escarificadas de $U$. brizantha e concluiu que a superação da dormência durante o armazenamento foram conseguidos a 50 e $40^{\circ} \mathrm{C}$, respectivamente.

Estas respostas aparentemente discrepantes observadas na literatura e também obtidas nesse trabalho, considerando as respostas de lotes com maior e menor vitalidade, podem ser explicadas por meio da "janela oxidativa para germinação", onde baixos ou altos conteúdos de ROS, respectivamente, não permitiriam progresso em direção à germinação. Em situações de incontrolado acúmulo de ROS acorrerá dano oxidativo afetando muitas macromoléculas e culminando com morte celular (BAILLY et al., 2008). 
Tabela 3. Número de sementes remanescentes dormentes ${ }^{1}$ (\%) de três lotes de U. humidicola cv. Tully.

\begin{tabular}{lcccc}
\hline Tratamentos & & L2 & L4 & L6 \\
\cline { 3 - 5 } $\mathbf{P}$ & $\mathbf{T}$ & & & $9 \pm 1,26$ \\
\hline 24 & 45 & $8 \pm 2,65^{2}$ & $9 \pm 1,29$ & $7 \pm 0,96$ \\
& 55 & $6 \pm 1,50$ & $6 \pm 3,11$ & $4 \pm 1,15$ \\
& 65 & $6 \pm 2,38$ & $6 \pm 2,38$ & $6 \pm 2,89$ \\
48 & 75 & $8 \pm 2,45$ & $6 \pm 2,06$ & $9 \pm 1,29$ \\
& 45 & $10 \pm 2,16$ & $8 \pm 0,96$ & $7 \pm 2,16$ \\
& 55 & $10 \pm 4,83$ & $8 \pm 2,64$ & $9 \pm 3,11$ \\
& 65 & $8 \pm 3,32$ & $6 \pm 1,41$ & $3 \pm 1,00$ \\
Testemunha & 75 & $5 \pm 1,41$ & $4 \pm 1,63$ & $9 \pm 1,50$ \\
$\mathrm{H}_{2} \mathrm{SO}_{4}$ & & $11 \pm 2,36$ & $10 \pm 2,22$ & $4 \pm 1,26$
\end{tabular}

$\mathrm{P}=$ período $(\mathrm{h}) ; \mathrm{T}=$ temperatura $\left({ }^{\circ} \mathrm{C}\right) ; \mathrm{L}$ lotes. ${ }^{1}$ Sementes remanescentes, com as partes vitais do embrião coloridas pelo teste de tetrazólio, no teste de germinação (\%). ${ }^{2}$ Médias seguidas por desvio padrão (2 repetições).

De acordo com Oliveira e Mastrocola (1983), o ácido sulfúrico interfere negativamente na germinação das sementes de $U$. humidicola colhidas há mais de 10 meses. O que de fato aconteceu com os lotes com menor vitalidade analisadas neste estudo, levando a crer que o uso de ácido sulfúrico causou a danificação das membranas celulares.

O índice de velocidade de germinação (Tabela 4), indicou no lote 1 , que o período de $24 \mathrm{~h}$ com temperaturas de 45 e 65 o $\mathrm{C}$ e período de $48 \mathrm{~h}$ com temperaturas de 45 e $55^{\circ} \mathrm{C}$, foram iguais ao tratamento com $\mathrm{H}_{2} \mathrm{SO}_{4}$ e a testemunha. Os demais tratamentos foram inferiores à testemunha.

Para o lote 2 , apenas o período de $24 \mathrm{~h}$ com temperatura de 65 oc mostrou-se superior aos demais tratamentos, inclusive ao tratamento convencional e a testemunha. $\mathrm{E}$ no lote 3 , o período de $24 \mathrm{~h}$ com temperatura de 65 o $C$ e o período de $48 \mathrm{~h}$ com temperaturas de 55 e 65 ำ não diferiram em comparação ao tratamento convencional e à testemunha. Os outros tratamentos foram inferiores ao convencional e a testemunha (Tabela 4).

No lote 5, o tratamento de $48 \mathrm{~h}$ com temperatura de 65 e $75 \stackrel{\circ}{\circ}$, foram iguais aos tratamento convencional e a testemunha, sendo que os outros tratamento foram inferiores. Para os lotes 4 e 6 não verificou-se diferença entre os tratamentos os controles (Tabela 4). 
Tabela 4. Resultados de índice de velocidade de germinação de sementes de seis lotes de $U$. humidicola cv. Tully.

\begin{tabular}{lcccccccc}
\hline Tratamentos & & L1 & L3 & L5 & L2 & L4 & L6 & Médias \\
\cline { 2 - 8 } $\mathbf{P}$ & $\mathbf{T}$ & & & & & & & \\
\hline 24 & 45 & $3,46 \mathrm{a}$ & $2,47 \mathrm{~b}$ & $1,57 \mathrm{~b}$ & $3,33 \mathrm{~b}$ & $1,63 \mathrm{a}$ & $0,80 \mathrm{a}$ & 2,21 \\
& 55 & $2,89 \mathrm{~b}$ & $2,67 \mathrm{~b}$ & $1,25 \mathrm{~b}$ & $2,49 \mathrm{~b}$ & $1,32 \mathrm{a}$ & $0,75 \mathrm{a}$ & 1,90 \\
& 65 & $4,01 \mathrm{a}$ & $3,38 \mathrm{a}$ & $2,12 \mathrm{~b}$ & $4,31 \mathrm{a}$ & $1,40 \mathrm{a}$ & $0,53 \mathrm{a}$ & 2,63 \\
& 75 & $1,92 \mathrm{~b}$ & $1,74 \mathrm{~b}$ & $1,43 \mathrm{~b}$ & $1,79 \mathrm{c}$ & $1,15 \mathrm{a}$ & $0,45 \mathrm{a}$ & 1,41 \\
& 45 & $3,88 \mathrm{a}$ & $2,21 \mathrm{~b}$ & $1,36 \mathrm{~b}$ & $2,50 \mathrm{~b}$ & $1,56 \mathrm{a}$ & $1,39 \mathrm{a}$ & 2,15 \\
& 55 & $4,58 \mathrm{a}$ & $3,31 \mathrm{a}$ & $1,71 \mathrm{~b}$ & $1,34 \mathrm{c}$ & $1,74 \mathrm{a}$ & $1,01 \mathrm{a}$ & 2,28 \\
& 65 & $2,07 \mathrm{~b}$ & $3,54 \mathrm{a}$ & $2,64 \mathrm{a}$ & $2,52 \mathrm{~b}$ & $1,59 \mathrm{a}$ & $2,26 \mathrm{a}$ & 2,44 \\
& 75 & $2,36 \mathrm{~b}$ & $2,08 \mathrm{~b}$ & $2,56 \mathrm{a}$ & $1,59 \mathrm{c}$ & $0,67 \mathrm{a}$ & $0,92 \mathrm{a}$ & 1,70 \\
Testemunha & & $3,34 \mathrm{a}$ & $3,52 \mathrm{a}$ & $3,68 \mathrm{a}$ & $2,84 \mathrm{~b}$ & $1,05 \mathrm{a}$ & $1,15 \mathrm{a}$ & 2,60 \\
$\mathrm{H}_{2} \mathrm{SO}_{4}$ & & $3,54 \mathrm{a}$ & $3,81 \mathrm{a}$ & $3,17 \mathrm{a}$ & $1,33 \mathrm{c}$ & $0,00 \mathrm{a}$ & $0,34 \mathrm{a}$ & 2,03 \\
\hline Médias & & 3,21 & 2,87 & 2,15 & 2,40 & 1,21 & 0,96 &
\end{tabular}

$\mathrm{P}=$ período $(\mathrm{h}) ; \mathrm{T}=$ temperatura $\left({ }^{\circ} \mathrm{C}\right) ; \mathrm{L}=$ lotes; ${ }^{1}$ Médias seguidas por mesma letra, na coluna, não diferem pelo teste Scott-Knott, com $5 \%$ de significância

Analisando os dados de massa seca de plântulas (Tabela 5), observa-se que, no lote 1, o período de $24 \mathrm{~h}$ com temperaturas de 45 e $65 \stackrel{\circ}{\circ}$ e o período de $48 \mathrm{~h}$ com temperaturas de 45 e 55 o C, foram superiores estatisticamente aos demais.

Tabela 5. Massa seca de plântulas (g) provenientes de sementes de seis lotes de U. humidicola cv. Tully

\begin{tabular}{lcccccccc}
\hline Tratamentos & & L1 & L3 & L5 & L2 & L4 & L6 & Médias \\
\cline { 2 - 9 } $\mathbf{P}$ & $\mathbf{T}$ & & & & $\mathbf{( g )}$ & & & \\
\hline 24 & 45 & $0,051 \mathrm{a}$ & $0,046 \mathrm{~b}$ & $0,028 \mathrm{c}$ & $0,035 \mathrm{a}$ & $0,019 \mathrm{a}$ & $0,009 \mathrm{a}$ & 0,031 \\
& 55 & $0,038 \mathrm{~b}$ & $0,046 \mathrm{~b}$ & $0,020 \mathrm{c}$ & $0,033 \mathrm{a}$ & $0,018 \mathrm{a}$ & $0,010 \mathrm{a}$ & 0,028 \\
& 65 & $0,063 \mathrm{a}$ & $0,058 \mathrm{a}$ & $0,031 \mathrm{c}$ & $0,042 \mathrm{a}$ & $0,021 \mathrm{a}$ & $0,005 \mathrm{a}$ & 0,037 \\
& 75 & $0,041 \mathrm{~b}$ & $0,028 \mathrm{c}$ & $0,022 \mathrm{c}$ & $0,027 \mathrm{a}$ & $0,015 \mathrm{a}$ & $0,004 \mathrm{a}$ & 0,023 \\
& 45 & $0,054 \mathrm{a}$ & $0,038 \mathrm{~b}$ & $0,023 \mathrm{c}$ & $0,033 \mathrm{a}$ & $0,020 \mathrm{a}$ & $0,015 \mathrm{a}$ & 0,031 \\
& 55 & $0,054 \mathrm{a}$ & $0,054 \mathrm{a}$ & $0,027 \mathrm{c}$ & $0,005 \mathrm{~b}$ & $0,024 \mathrm{a}$ & $0,010 \mathrm{a}$ & 0,029 \\
& 65 & $0,032 \mathrm{~b}$ & $0,065 \mathrm{a}$ & $0,043 \mathrm{~b}$ & $0,034 \mathrm{a}$ & $0,019 \mathrm{a}$ & $0,023 \mathrm{a}$ & 0,036 \\
& 75 & $0,043 \mathrm{~b}$ & $0,028 \mathrm{c}$ & $0,051 \mathrm{~b}$ & $0,021 \mathrm{a}$ & $0,007 \mathrm{a}$ & $0,010 \mathrm{a}$ & 0,027 \\
Testemunha & & $0,025 \mathrm{~b}$ & $0,063 \mathrm{a}$ & $0,069 \mathrm{a}$ & $0,032 \mathrm{a}$ & $0,012 \mathrm{a}$ & $0,012 \mathrm{a}$ & 0,036 \\
$\mathrm{H}_{2} \mathrm{SO}_{4}$ & & $0,036 \mathrm{~b}$ & $0,063 \mathrm{a}$ & $0,054 \mathrm{~b}$ & $0,008 \mathrm{~b}$ & $0,000 \mathrm{a}$ & $0,004 \mathrm{a}$ & 0,028 \\
\hline Médias & & 0,0437 & 0,0489 & 0,0368 & 0,027 & 0,0155 & 0,0102 &
\end{tabular}

$\mathrm{P}=$ período $(\mathrm{h}) ; \mathrm{T}=$ temperatura $\left({ }^{\circ} \mathrm{C}\right) ; \mathrm{L}=$ lotes. ${ }^{1}$ Médias seguidas por mesma letra, na coluna, não diferem pelo teste Scott-Knott, com $5 \%$ de significância 
Para o lote 2 (Tabela 5), o período de $24 \mathrm{~h}$ com temperatura de $45,55,65$ e $75 \stackrel{\circ}{ } \mathrm{C}$ e o período de $48 \mathrm{~h}$ com temperatura de 45,65 e 75 óC não diferiram-se da testemunha, sendo superiores ao tratamento convencional. $\mathrm{O}$ tratamento de $48 \mathrm{~h}$ com temperatura de 55 C não deferiu em relação ao tratamento convencional.

No lote 3 , o período de $24 \mathrm{~h}$ com temperatura de 65 o $\mathrm{C}$ e o período de $48 \mathrm{~h}$ com temperaturas de 55 e 65 o C não diferiram em relação ao tratamento convencional e à testemunha, porém foram superiores aos demais tratamentos (Tabela 5).

No lote 5, a testemunha foi melhor estatisticamente do que todos tratamentos aplicados (Tabela 5), levando a crer que o lote 5 não suportou o tratamento com temperatura e ácido sulfúrico corroborando com a observação de Macedo et al. (1994), em sementes de $U$. humidicola, e por Gonzáles et al. (1994) em sementes de U. decumbens. Para os lotes 4 e 6 não foram encontradas diferenças entre os tratamentos (Tabela 5).

A resposta, dos lotes aos tratamentos, avaliados pelos testes de vigor, índice de velocidade de germinação e massa seca de plântulas, seguiu a tendência discutida para as variáveis germinação e sementes remanescentes dormentes.

Embora, de maneira geral, não tenham sido obtidos resultados expressivos para o uso do calor seco, as respostas obtidas para os lotes 3, com indicação de pontos de máximo próximos aos $60^{\circ} \mathrm{C}$ e ajustes lineares crescentes para o lote 5 corroboram com resultados obtidos por outros estudos (ALMEIDA; SILVA, 2004; MARTINS; SILVA, 2006).

\section{CONCLUSÕES}

A análise de regressão, de maneira geral, não indica o melhor período para emprego da ventilação (24 ou 48h) com ar seco.

A temperatura de $60^{\circ} \mathrm{C}$, para lotes de maior vitalidade, pode ser recomendada.

$\mathrm{O}$ uso de $\mathrm{H}_{2} \mathrm{SO}_{4}$ em lotes com menor vitalidade acarreta deterioração fisiológica das sementes.

\section{REFERÊNCIAS}

ALMEIDA, C.R.; SILVA, W.R. Comportamento da dormência em sementes de Brachiaria dictyoneura cv. Llanero submetidas às ações do calor e do ácido sulfúrico. Revista Brasileira de Sementes, v.26, n.1, p.44-49, 2004. http://dx.doi.org/10.1590/s0101$\underline{31222004000100007}$

ALVARADO, V.; BRADFORD, K.J. A hydrothermal time model explains the cardinal temperatures for seed germination. Plant, Cell and Environment, v.25, n.8, p.1061-1069, 2002. http://dx.doi.org/10.1046/j.13653040.2002.00894.x

BAILLY, C.; EL-MAAROUF-BOUTEAU, H.; CORBINEAU, F. From intracelular signaling networks to cell death: the dual role of reactive oxygen species in seed physiology. 
Comptes Rendus Biologies, v.331, n.10, p.806-814, 2008. <http://dx.doi.org/10.1016/j.crvi.2008.07.02 2>

BRASIL. Instrução Normativa no 30 , de 21 de maio de 2008. Normas e padrões para produção e comercialização de sementes de espécies forrageiras de clima tropical. Diário Oficial da União, Brasília, DF, 23 de mai. 2008.

Disponível: <http://www.indea.mt.gov.br/arquivo/Aa953 b706c8e7418b71a4c77525bc3776INF302008.pdf> Acesso em: 09 de ago. 2012.

BRASIL. Ministério da Agricultura, Pecuária e Abastecimento. Regras para análise de sementes. Ministério da Agricultura, Pecuária e Abastecimento. Secretaria de Defesa Agropecuária. Brasília, DF: Mapa/ACS, 2009. $395 p$.

CUSTÓDIO, C.C., DAMASCENO, R. L.; MACHADO NETO, N. B. Imagens digitalizadas na interpretação do teste de tetrazólio em sementes de Brachiaria brizantha. Revista Brasileira de Sementes, v.34, n.2, p.334-341, 2012. <http://dx.doi.org/10.1590/S010131222012000200020>

CUSTÓDIO, C.C.; AMBIEL, A.C.; RODRIGUES, D.Z.; AGOSTINI, E.A.T.; FACTUR, V.; PAVANELLI, L.E. Peliculização de sementes intactas e escarificadas de Brachiaria brizantha (Hochst. ex A. Rich.) Stapf. Pesquisa Agropecuária Tropical, v.41, n.3, p.314-321, 2011. <http://dx.doi.org/10.5216/pat.v41i3.9146>

FERRAZ, F.M. Pastures ensure the future of dairy cattle ranching. In: Anualpec 2003: Anuário da pecuária brasileira. São Paulo: FNP, 2003. p. 55-56.

FERREIRA, D.F. Sisvar: a computer statistical analysis system. Ciência e Agrotecnologia, v.35, p.1039-1042, 2011.

FINCH-SAVAGE, W.E., LEUBNER-METZGER, G. Seed dormancy and the control of germination. New Phytologist, v.171, n.3, p.501-523, 2006. <http://dx.doi.org/10.1111/j.1469-

8137.2006.01787.x>

FOLONI, J.S.S.; CUSTÓDIO, C.C.; CALDEIRA, F.J.; LOUREIRO CALVO, C. Emergência de plântulas de Brachiaria brizantha influenciada por escarificação das sementes, uso de adubo e profundidade de semeadura. Científica, v.37, n.2, p.89-97, 2009. $<$ http://cientifica.org.br/index.php/cientifica/ article/view/285/156>

GONZÁLEZ, Y.; MENDOZA, F.; TORRES, R. Efecto del almacenamiento y la escarificación química y mecánica sobre las semillas de Brachiaria decumbens cv. Basilisk. Pastos y Forrajes, v.17, n.35, p.35-43, 1994.

GREGGAINS, V.; FINCH-SAVAGE, W.E.; ATHERTON, N.M.; BERJAK, P. Viability loss free radical processes during desiccation of recalcitrant Avicennia marina seeds. Seed Science Research, v.11, n.3, p.235-242, 2001. <http://dx.doi.org/10.1079/SSR200179>

HOPKINSON, J.M.; ENGLISH, B.H. Influence of storage conditions on survival and sowing value of seed of tropical pasture grasses. 2 . Sowing value and storage strategies. Tropical Grasslands, v.39, n.3, p.140-151, 2005. <http://www.tropicalgrasslands.asn.au/Tropi cal\%20Grasslands\%20Journal\%20archive/PDF s/Vol_39_2005/Vol_39_03_2005_pp140_151 .pdf>

IBGE - Instituto Brasileiro de Geografia e Estatística. Censo da Agropecuária 2006. IBGE, Rio de Janeiro, RJ, Brasil.

LIMA, V.L.; CARDOSO, V.J.M. On the germination and dormancy of dispersal units of Brachiaria decumbens Stapf. Arquivos de Biologia e Tecnologia, v.39, n.3, p.595-606, 1996.

MACEDO, E.C.; GROTH, D.; LAGO, A.A. Efeito de escarificação com ácido sulfúrico na germinação de sementes de Brachiaria 
humidicola (Rendle) Schw. Pesquisa Agropecuária Brasileira, v.29, n.3, p. 455460, 1994.

MARTINS, L.; SILVA, W.R. Comportamento da dormência em sementes de braquiária submetidas a tratamentos térmicos e químicos. Pesquisa Agropecuária Brasileira, v.36, n.7, p.997-1003, 2001. < http://seer.sct.embrapa.br/index.php/pab/ar ticle/view/6222/3287>

MARTINS, L.; SILVA, W.R. Efeitos imediatos e latentes de tratamento térmico e químico em sementes de Brachiaria brizantha cultivar Marandu. Bragantia, v.62, n.1, p.83-89, 2003. http://dx.doi.org/10.1590/S000687052003000100011

MARTINS. L.; SILVA, W.R. Ações fisiológicas do calor e do ácido sulfúrico em sementes de Brachiaria brizantha cultivar Marandu. Bragantia, v.65, n.3, p.495-500, 2006. <http://dx.doi.org/10.1590/S000687052006000300016>

MARTINS, L.; SILVA, W.R; LOT, R.C. Tratamentos térmicos e superação da dormência em sementes de Brachiaria brizantha (Hoechst. ex A. Rich) Stapf. Informativo ABRATES, v.7, n. 1 e 2, p.245, 1997.

MESCHEDE, D.K.; SALES, J.G.C.; BRACCINI, A.D.L., SCAPIM, C.A.; SCHUAB, S.R.P. Tratamentos para superação da dormência das sementes de capim braquiária cultivar Marandu. Revista Brasileira de Sementes, v.26, n.2, p.76-81, 2004. http://dx.doi.org/10.1590/s0101-

\section{$\underline{31222004000200003}$}

MONTÓRIO, G.A.; BRACCINI, A.L.; SCAPIM, C.A.; OLIVEIRA, V.R.; BRACCINI, M.C.L. Avaliação de métodos para superação da dormência das sementes de capim braquiária (Brachiaria brizantha cv. Marandu). Revista Unimar, v.19, n.3, p.797-809, 1997. <http://eduem.uem.br/ojs/index.php/RevUN IMAR/article/view/4560/3110>
NAKAGAWA, J. Testes de vigor baseados nos desempenhos das plântulas. In: KRZYZANOWSKI, F.C.; VIEIRA, R.D.; FRANÇA NETO, J.B. (Ed.). Vigor de sementes: conceitos e testes. Londrina: ABRATES, 1999. p.2.1-2.24.

OLIVEIRA, P.R.P.; MASTROCOLA, M.A. Brachiaria humidicola (Rendle) Schweickedert: viabilidade de suas sementes. Boletim de Industria Animal, v.40, n.1, p.4953, 1983.

ORACZ, K.; EL-MAAROUF BOUTEAU, H.; FARRANT, J.M.; COOPER, K.; BELGHAZI, M.; JOB, C., JOB, D.; CORBINEAU, F.; BAILLY, C. ROS production and protein oxidation as a novel mechanism for seed dormancy alleviation. The Plant Journal, v.50, n.3, p.452-465, 2007. $<$ http://dx.doi.org/10.1111/j.1365313X.2007.03063.x>

PIRES, W. Manual de pastagem: Formação, Manejo e Recuperação: O que plantar. (Ed.). Viçosa: Aprenda Fácil, 2006, p. 59-119.

SALLUM, M.S.S.; ALVES, D. S.; AGOSTINI, E. A. T.; MACHADO NETO, N.B. Neutralização da escarificação química sobre a germinação de sementes de Brachiaria brizantha cv. 'Marandu'. Revista Brasileira de Ciências Agrárias, v.5, n.3, p.315-321, 2010. <http://dx.doi.org/10.5039/agraria. v5i3a603>

SILVA, T.T.A.; OLIVEIRA, J.A.; CARVALHO, M.L.M.D.; VIEIRA, A.R.; COSTA, R.R.; ABREU, L.A.D.S. Teor de água na colheita $e$ temperatura de secagem na qualidade de sementes de sorgo, durante o armazenamento. Revista Brasileira de Milho e Sorgo, v.10, n.1, p.66-81, 2011. http://rbms.cnpms.embrapa.br/index.php/oj s/article/viewFile/317/430

THOMPSON, K.; OOI, M.K.J. To germinate or not to germinate: more than just a question of dormancy. Seed Science Research, v.20, 
n.4, p.209-211, 2010.

<http://journals.cambridge.org/article_S0960 258510000267>

USBERTI, R. Performance of tropical forage grass (Brachiaria brizantha) dormant seeds under controlled storage. Seed Science and Technology, v.35, n.2, p. 402-413, 2007. <http://www.ingentaconnect.com/content/is ta/sst/2007/00000035/00000002/art00015>

USBERTI, R.; MARTINS, L. Sulphuric acid scarification effects on Brachiaria brizantha, B. humidicola and Panicum maximum seed dormancy release. Revista Brasileira de Sementes, v.29, n.2, p.143-147, 2007. <http://dx.doi.org/10.1590/S0101-

31222007000200020>

VERDOY, D.; LUCAS, M.M.; MANRIQUE, E.; COVARRUBIAS, A.A.; DE FELIPE, M.; PUEYO, J.J. Differential organ-specific response to salt stress and water deficit in nodulated bean (Phaseolus vulgaris). Plant Cell and Environment, v.27, n.6, p.757-767, 2004. <http://dx.doi.org/10.1111/j.1365-

3040.2004.01179.x>

WATT, M.S.; BLOOMBERG, M. Key features of the seed germination response to high temperatures. New Phytologist, v.196, n.2, p. 332-336, 2012. <http://dx.doi.org/10.1111/j.1469-

8137.2012.04280.x> 